\title{
Experimental investigation in machining EN18 using coated tool under dry and MQL condition
}

\author{
Kosaraju Satynarayana ${ }^{1, *}$, Kumkuma Rajkiran ${ }^{2}$, Kalemula Sai Kiran $^{2}$ \\ ${ }^{1}$ Assoc.Professor, GRIET, Mechanical Engineering Department, Bachupally 500090, Hyderabad, India. \\ ${ }^{2}$ PG Student, GRIET, Mechanical Engineering Department, Bachupally 500090, Hyderabad, India.
}

\begin{abstract}
EN 18 is one of the versatile metal that exists its presences in all the industrial, transportation and building equipment's. Machining of these material is done on large scale and consumes a whole lot of lubrication unit. Present paper discuss regarding the usage and substitutional to flood coolant systems by minimum quality lubrication ((MQL) systems for economical friendly green machining operation. Using three-factor parameters speed $(50,75,100 \mathrm{~m} / \mathrm{min})$, feed $(0.05,0.1,0.15 \mathrm{~mm} / \mathrm{rev})$ and depth of cut $(0.4,0.8$, $1.2 \mathrm{~mm}$ ) are varied and turned on the EN 18 steel. The experimental outcomes of surface roughness is discussed with comparison with dry machining and ST-CUT 54 MQL machining. It was observed that with MQL turning the roughness produce better compared to dry machining. The optimum condition was found to be cutting speed at $100 \mathrm{~m} / \mathrm{min}$, feed at $0.05 \mathrm{~mm} / \mathrm{rev}$ and depth of cut at $0.4 \mathrm{~mm}$. The outcomes are useful for improved machining industrial practices.
\end{abstract}

\section{INTRODUCTION}

Rate of production has been increased to a wide scale globally. This evaluation in use of metal cutting fluids and lubrications in large scales. Industries and governing bodies are now focusing on reducing the use of this global misbalancing fluids with compensating them with minimum or micro level use of lubricants [1]. Beyond the use, lubricants also effects the skin, in order to despite the problems with the lubricants researchers have been performed using the minimum quantity lubrications [2], which was further termed as nearby dry lubrication [3] and further as micro-lubrication [4]. In traditional practices, the problems such as cutting forces, cutting temperature and tool wear was efficiently overcome by use of flood lubrications [5]. In majority, the cost of production also included the disposable costs, it add up high value on cost of machining [6]. MQL is one which one of the intense research topic and state- of -art that concludes the all the environmental and mechanical cutting problems. Minimum quantity lubrication is one such which utilizes the very small amount of lubricant or coolants which may range from $50 \mathrm{ml} / \mathrm{hr}$ to $100 \mathrm{ml} / \mathrm{hr}$. in one of the research $\mathrm{M}$. Rahman et al. [7] proved that 42 $1 / \mathrm{min}(25,20,000 \mathrm{ml} / \mathrm{hr})$ of liquid by minimized to 8.5 $\mathrm{ml} / \mathrm{h}$ vegetable oil while machining s ASSAB $718 \mathrm{HH}$ of 35 HRc with MQL flow. Authors concluded saying that $1 / 3,00,000$ times of lubricant consumption was reduced to gain a comparative parameters of flood and MQL.

Mass production of fabrication of steel components inherently produces a high amount of temperature and tool wear. This results in dimensional errors or remanufacturing efforts. Temperature and tool wear are the contributing factors for the micro-cracks, raise in residual stresses and surface integrity.[8]. Usage of MQL fluid on industrial shop floor produces a large amount of smoky vision, with oily humidification. [9]. In safe guarding the health, these MQL oil used are extracted from the vegetables which are bio-degradable and nontoxic [10]. Petroleum based oils are also used as MQL but under high level of precautions. Researches have been conducted using solid particles as lubricants. These solid lubricating natured solid particles are grounded to Nano size and then mixed with oils. Then is mixture of Nano-particles and oils are sprayed over the work are as the MQL lubrication. Nano MoS2 with vegetable oils [11], Al2o3 with water [12], graphite with distilled water [13], boron oil which was prepared from diluting it with distilled water [14] and so on. Form the literature survey it was concluded that boron mixed based Nano- MQL shown a major difference in surface integrity. In the present work to study the effect of processes parameters in turning of EN18 with TiN coated tool under dry and MQL condition and regression equations are generated based on the experimental data obtained. In addition to that an ANOVA analysis was performed to know the most significant process parameter which effect the performance characteristics.

\section{Experimentation}

\subsection{MATERIAL AND METHOD}

EN 18 graded steel material was procured by the commercially available source and was under gone chemical analysis process to find the alloy percent in it. A full factorial design of experiments were planned with

\footnotetext{
* Corresponding author: author@e-mail.org
} 
machining parameters mentioned in Table 1, Machining was done on $60 \mathrm{~mm}$ length, $48 \mathrm{~mm}$ dia and each experiment was conducted on separate workpieces with new coated tool. Experiments were conducted both at dry and MQL conditions on precision lathe Pinacho SC200 lathe shown in Figure 1 and Figure 2. For the MQL lubrication fluids, ST-cut 54 divyol oil of Ghandhar make was used. Due to its high fluidity, this oil is majorly used in threading, tapping, and boring, reaming and drilling operations. The effect of non-toxic and noflumes produced while using this oil, made it be used under this research process. Straight cutting oils are usually insoluble oils that have high temperature absorbing capabilities. They are low toxic and nonoxidizing by nature.

Table 1. Turning parameters and their levels

\begin{tabular}{|l|l|l|l|l|}
\hline $\begin{array}{l}\text { Machining } \\
\text { parameters }\end{array}$ & $\begin{array}{l}\text { Notation } \\
\text { (units) }\end{array}$ & Level-1 & Level-2 & Level-3 \\
\hline Speed & $v(\mathrm{~m} / \mathrm{min})$ & 50 & 75 & 100 \\
\hline Feed & $f(\mathrm{~mm} / \mathrm{rev})$ & 0.05 & 0.1 & 0.15 \\
\hline Depth of cut & $d(\mathrm{~mm})$ & 0.4 & 0.8 & 1.2 \\
\hline
\end{tabular}

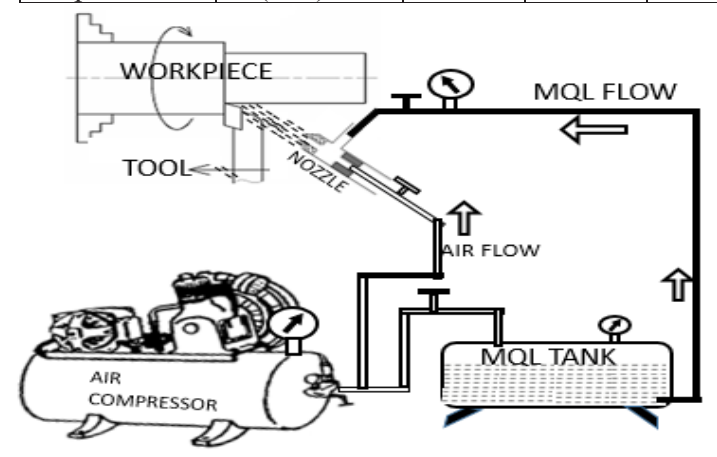

Fig. 1. Layout of experimental set-up

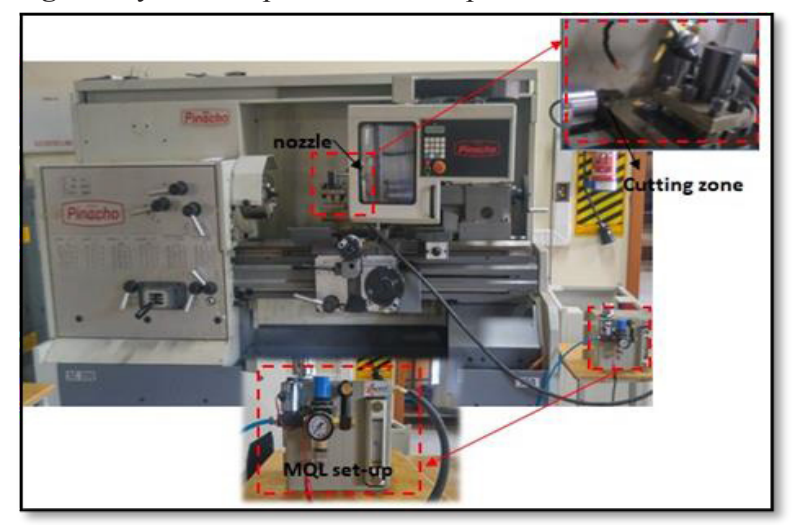

Fig. 2. Experimental Set-up

\subsection{Roughness Measurement}

surface roughness was measured with test and trail at 3 different location with the aid of probe type surface roughness tester of Zeiss made surfcom flex tester with a cut-off length of $0.8 \mathrm{~mm}$. Surface roughness has been calculated with consideration of 3 trial values at random places over the surface. Considering those values, the average of these 3 values are considered and reported in the form of graphs.

\section{Results and Discussion}

After consideration of all the surface roughness values in case of dry and MQL graphs are plotted. As CNMG insert were used in experimentation which has an inner rake face adjacent (groove) to the cutting plane. This groove acted as the flow passenger for the MQL fluid to pass through it and there by the MQL fluid has obtained its best in reaching the cutting, shearing zone. Due to this phenomena, a reasonable differences were observed in all cases between surface roughness of dry and MQL turning. And also it is observed form the results that machining with MQL give lower surface roughness values (Better surface finish) compare to Dry machining. Low surface roughness was observed on high speeds which practically proves that friction occurrence is low at high turning speed. Due to low friction between tool and workpiece and also due to fast revolutions, a good surface can be obtained. This work is also conforms the past works done by Alauddin et al. [15] states that increase in speed increases the production rate and also improves surface roughness. The major factors that plays a vital role in lowering surface finish are feed rate. In the previous works it was proved that feed rate is one which increases or decreases the surface roughness $[16,17]$.

\subsection{Effect of cutting speed on surface roughness}

Speed is one of the major factor that deals with the performance characteristics of tool wear, and effect on hard to cut materials [18]. Super alloys, heavy machineries [19] are usually performed at low speed in order to compensate with tool life and heavy cuts with high cutting forces. Increase in cutting speed increases the tangential forces and contributes in high power consumption criteria. With high speeds low surface roughness values was observed in all the 3 level of depth of cuts shown in Figure 3. In the following graphs plotted with constant feed of $0.1 \mathrm{~mm} / \mathrm{rev}$, cutting speed is plotted with surface roughness. With combination of higher speed with low depth of cut at $0.4 \mathrm{~mm}$ a superior surface roughness has been noticed. Figures are drawn at constant feed rate $0.1 \mathrm{~mm} / \mathrm{rev}$.

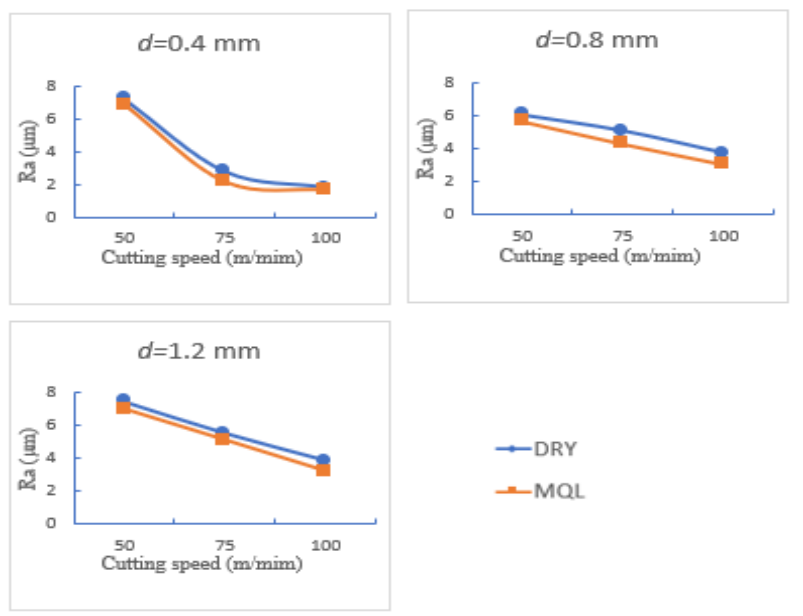

Fig. 3. Variation of surface roughness wrt speed 


\subsection{Effect of feed on surface roughness}

Figure 4 shows the plots at various speeds and feeds at constant depth of cut of $1.2 \mathrm{~mm}$. Feed rate is one of the parameter that deals with machining time. The higher the feed rate, the faster the tool movement and lower the machining time [20]. On the other side, feed is the factor that dominates in the role of flank wear of the tool because due to fast rapid movement of tool on the workpiece leads to more wear of tool. Alias et al [21] has experimentally proves that low feed rate created more creates on the surface of material than at high feed rates. From the following fig 4 . it can be clearly plotted that at low feed of 0.05 at low speed performed low surface roughness. With low feeds, there can be ability for chip breaker and temperature dissipation from the tool and work piece. Major effect on the surface finish in all the machining conditions. In few conditions, the rate of tool wear depends on factors such as speed and feed. The higher the feed rate, the greater the tool wear. The greater the tool wear, the greater the surface roughness of the machined surface. Figures drawn at constant Depth of cut $1.2 \mathrm{~mm}$.

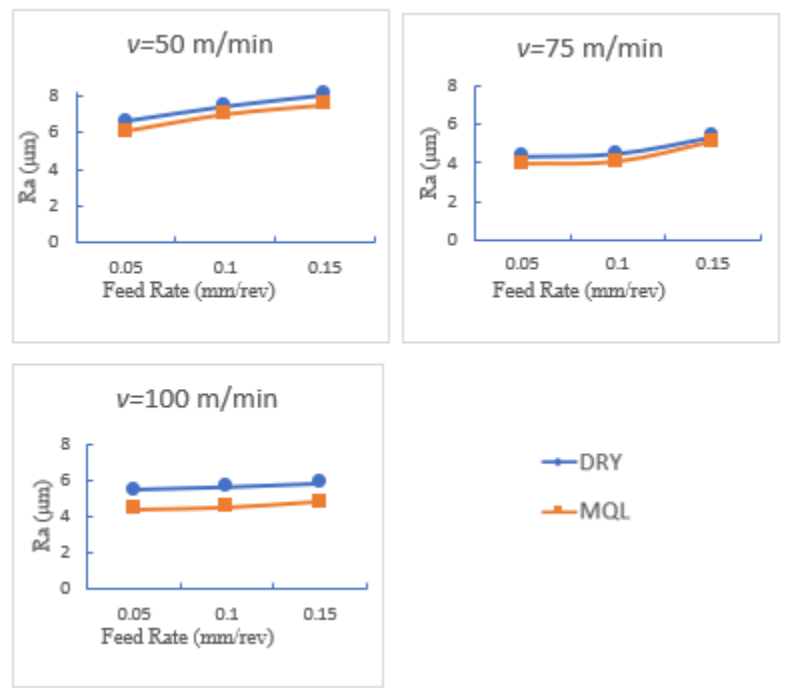

Fig. 4. Variation of surface roughness wrt feed

\subsection{Effect of Depth of cut on surface roughness}

Depth of cut can be also termed as the rating factor that tunes the material removal rate. The higher the depth of cut, the higher the material removal rate. But the draw backs of depth of cut is, tool breakage [22]. Nose radius of tool breaker while machining with high depth of cuts. Materials with low melting point such as composites and aluminium give raise to build up edge [23] formation. This is due to the high depth increases the cutting temperature and tends in weldability of work material on to the tool.in the present paper the effect of depth of cut can be clearly explained in Figure 5. Shows that increase in depth $f$ cut increases the surface roughness. At low feed of 0.05 in Figure 5 low surface roughness is observed. Key technical reason is as the depth increases it leaves the indentation of nose radius angle cuts in form of threading on combination of high depth and high feed. Figures are drawn at constant speed of $50 \mathrm{~m} / \mathrm{min}$

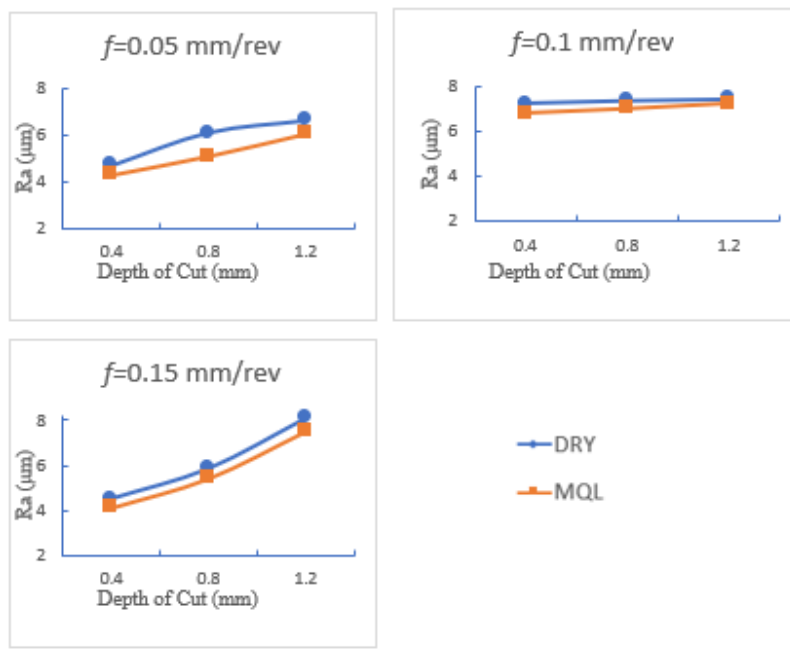

Fig. 5. Variation of surface roughness wrt depth of cut

\subsection{Optimum conditions}

From the experimental results it was observed that for machining EN18 with coated tool under the dry and MQL condition one should machine at cutting speed at level $3(100 \mathrm{~m} / \mathrm{min})$, feed at level $1(0.05 \mathrm{~mm} / \mathrm{rev})$ and depth of cut at level $1(0.4 \mathrm{~mm})$ and the values that obtained are shown in Table 2.

Table 2. optimum conditions for surface roughness

\begin{tabular}{|l|l|l|l|l|}
\hline Condition & Speed & Feed & $\begin{array}{l}\text { Depth } \\
\text { of cut }\end{array}$ & $\mathrm{Ra}$ \\
\cline { 2 - 5 } & $\mathrm{m} / \mathrm{min}$ & $\mathrm{mm} / \mathrm{rev}$ & $\mathrm{mm}$ & $\mu \mathrm{m}$ \\
\hline DRY & 100 & 0.05 & 0.4 & 1.482 \\
\hline MQL & 100 & 0.05 & 0.4 & 1.162 \\
\hline
\end{tabular}

\section{Conclusion}

Uncoated and TiN coated CNMG 120408 inserts were used for turning of EN 18 in semi-automatic precision lathe was performed. Experimentation was conducted at both dry and MQL condition. The following outcomes are concluded-

- MQL plays a vital role in lowering the surface roughness when compared to the dry machining.

- As the cutting speed increases the surface roughness decreases in both dry and MQL turning

- As the feed rate increases the surface roughness value increases in both dry and MQL turning

- As the depth of cut increases the surface roughness values increases in both dry and MQL turning

- Optimum condition from experiments found to be at cutting speed at level $3(100 \mathrm{~m} / \mathrm{min})$, feed at level $1(0.05 \mathrm{~mm} / \mathrm{rev})$ and depth of cut at level $1(0.4 \mathrm{~mm})$ 


\section{Reference}

1. Ali, S. M., Dhar, N. R., \& Dey, S. K. APEM, 6,3. (2011).

2. Tamang, S. K., Chandrasekaran, M., Palanikumar, K., \& Arunachalam, R. M ,Int. J. Mach. Mach. Mater, 21,1-2, 43-65, 43-65, (2019).

3. Singh, T., Singh, P., Dureja, J. S., Dogra, M., Singh, H., \& Bhatti, M. S., Int. J. Mach. Mach. Mater, 18, 3. 213-251 (2016).

4. Obikawa, T., Kamata, Y., Asano, Y., Nakayama, K., \& Otieno, A. W. Micro-liter lubrication machining of Inconel 718. Int. J. Mach. Tools Manuf., 48, 15. 1605-1612. (2008).

5. Jia, D., Li, C., Zhang, D., Zhang, Y., \& Zhang, X. J Nanopart Res, 16(12), 2758. (2014).

6. Byrne, G., \& Scholta, E. CIRP ANN-Manuf Techn, 42(1), 471-474, (1993).

7. Rahman, M., Kumar, A. S., \& Salam, M. U. Int. J. Mach, 42(5), 539-547, (2002).

8. H.K. Tonshoff, E. Brinkomeier CIRP ANN-Menuf Techn 29 (2) , 519-532 (1986)

9. Sadeghi, M. H., Haddad, M. J., Tawakoli, T., \& Emami, M. Int J Adv Manuf Tech. 44,5,. 487500.(2009).

10. Ni, J., Feng, G., Meng, Z., Hong, T., Chen, Y., \& Zheng, X. .Int J Adv Manuf Tech. 94,1-4. 10311040 . (2018).

11. Zhang, Y., Li, C., Jia, D., Zhang, D., \& Zhang, X. J. Clean. Prod. 87, 930-940 (2015).

12. Ghosh, S., and P. V. Rao. J. Clean. Prod 231, 10361049 (2019).

13. Yogeswara Reddy B, Srinivas Rao J, Suresh Kumar T, Nagarjuna A, Int. J. of Inn. Tech and Exp Engg., 8(11), 1194-1198, (2019)

14. Kursuncu, B., \& Yaras, A. Int J Adv Manuf Tech. 95,5-8, 2005-2013, (2018).

15. Alauddin, M., M. A. El Baradie, and M. S. J. Hashmi. J. Mater. Process. Technol. 71,3. 456-465. (1997).

16. Satyanarayana, Kosaraju, Anne Venu Gopal, and Popuri Bangaru Babu., ijmmm. 13(2-3), 191-202. (2013).

17. Kosaraju, Satyanarayana, M. Vijay Kumar, and N. Sateesh. Material Today 5,2 5343-5348. (2018)

18. Tansel, I., Trujillo, M., Nedbouyan, A., Velez, C., Bao, W. Y., Arkan, T. T., \& Tansel, B. Int. J. Mach. Tools Manuf. 38,12. 1449-1466. (1998)

19. Tummala Suresh Kumar, Kosaraju Satyanarayana, Materials Today: Proceeding, 26 (2), 3228-3233, (2020).

20. Kivak, T. Measurement, 50, 19-28. (2014).

21. Alias, A., Abdullah, B., \& Abbas, N. M. Procedia Eng, 41, 1812-1817. (2012).

22. Kumar, K. K., \& Choudhury, S. K. J. Mater. Process. Technol. 203,1-3, 95-101. (2008).

23. Sukvittayawong, S., \& Inasaki, I. Int. J. Mach. Tools Manuf. 34,6. 82-840 (1994). 